\title{
Engagement in Practice: STEM Engagement through Mentoring
}

\section{Prof. Mariam Manuel, University of Houston}

Mariam Manuel is a graduate of the University of Houston's teachHOUSTON program and the UTeach Engineering Master's program at the University of Texas at Austin. In Spring 2016, Mariam returned to the University of Houston to serve as an Instructional Assistant Professor / Master Teacher for teachHOUSTON. In this role, Mariam is charged with teaching and inspiring the next generation of high-quality math and science teachers through inquiry-based instruction and ongoing field experiences. Mariam also teaches Physics 4345 (Physics for Pre-Service Teachers), a course that connects middle school physics state standards with content knowledge and instructional strategies that are designed to enhance student learning. Mariam is also the one of the writers and instructors for the Preparing for AP Physics I Massive Open Online Course (MOOC), offered through the University of Houston. The MOOC has served over 10,000 students in more than 110 different countries.

Mariam previously served as the Instructional Specialist for the Robert Shaw Center for STEAM in the Katy Independent School District (KISD). She was responsible for implementing STEAM curriculum, instruction, and projects appropriate for K-12 students. Additionally, Mariam has taught both on-level and AP Physics I (formerly known as Pre-AP Physics) and played an integral role in writing the district physics curriculum consisting of rigorous labs, activities, and projects.

Mariam fills the role of Alumni Representative on the UTeach STEM Educators Association (USEA) Board and was also elected Secretary-Treasurer. She is also currently pursuing a Ph.D. in STEM education at Texas Tech University.

\section{Mr. Ricky P. Greer, University of Houston}

Ricky Greer graduated from Tuskegee University with a bachelor's in History. He went on to work at the University of Illinois at Urbana-Champaign as a community outreach specialist \& unit operations laboratory manager, and through his diligent work he earned the distinction as the Dr. Bruce D. Nesbitt Campus-Community Collaborator Awardee in 2016. Mr. Greer is also a co-founder of St. Elmo Brady STEM Academy (SEBA). SEBA is an educational intervention aimed at exposing underrepresented 4th and 5th grade boys to hands-on, inquiry based STEM activities. SEBA accomplishes its goals through an innovative educational curriculum and by engaging students' fathers and/or male mentors who learn STEM alongside them. This project has been recognized and funded by local organizations, University of Illinois and most recently, the National Science Foundation. Currently, Mr. Greer is enrolled in the Higher Education M. Ed program at the University of Houston. He is serving as a Graduate Assistant for the Urban Experience Program (UEP) in the Student Affairs Department. UEP provides opportunities for the university's diverse student population by preventing minor obstacles from becoming major setbacks to degree achievement. Mr. Greer has always had a passion for helping students succeed at navigating the college experience. He strives to promote academic awareness, academic excellence and the development of leadership skills in students. Ricky believes that anything is possible if you have faith and work hard to obtain your dreams. He believes that Dr. Martin Luther King Jr. said it best, "The function of education is to teach one to think intensively and to think critically. Intelligence plus character - that is the goal of true education."

\section{Dr. Jerrod A Henderson, University of Houston ( $\mathrm{CoE} \& \mathrm{CoT})$}

Dr. Jerrod A. Henderson ("Dr. J") is an Instructional Assistant Professor in the Cullen College of Engineering at the University of Houston. He joined the University of Houston after six years as a chemical engineering faculty member at the University of Illinois. He has dedicated his career to increasing the number of students who are in the pipeline to pursue STEM careers. He believes that exposing students to STEM early will have a lasting impact upon their lives and academic pursuits. He is the co-founder of the St. Elmo Brady STEM Academy (SEBA). SEBA is an educational intervention aimed at exposing underrepresented fourth and fifth grade boys to hands-on, inquiry based STEM experiments and activities. 


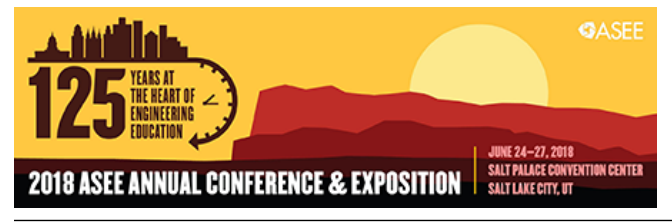

Henderson is a part of the first year engineering experience team and he was recently appointed by the Dean of the College as the Director of the Program for Mastery in Engineering Studies (PROMES), a program aimed at increasing engineering student achievement, engagement, and graduation rates. His research interests are in engineering identity formation and persistence among underrepresented students, especially African American males. He was most recently recognized by INSIGHT Into Diversity Magazine as an Inspiring STEM Leader Award recipient.

\section{Dr. Virginia Snodgrass Rangel Rangel, University of Houston}

Virginia Snodgrass Rangel, Ph.D. is an Assistant Professor in the Department of Educational Leadership and Policy Studies at the University of Houston, where she teaches courses on program evaluation, research design, and quantitative research methods. Her research interests include STEM education, reentry of justice-involved youth, policy implementation and evaluation, and program evaluation. 


\section{Engagement in Practice: STEM Engagement through Mentoring (SEM)}

\section{Problem Statement}

The declining levels of U.S. student achievement in mathematics and science were brought into focus by the President's Council of Advisors on Science and Technology, which stated that the U.S., especially at the elementary and secondary levels, is struggling to remain competitive with other nations in STEM education (PCAST, 2010). Furthermore, according to a report issued by the National Assessment of Educational Progress (NCES, 2015), less than 30 percent of students enrolled in the U.S. are proficient in the areas of science or mathematics. The landscape becomes more troubling when one considers mathematics and science performance among students who traditionally are underrepresented (UR) in science, technology, engineering, and mathematics (STEM) education and careers. These students include African Americans, Latinos, Native Americans, Pacific Islanders, students with special learning needs, and women. For instance, according to NAEP, fourth grade African American students scored on average 24 points lower than their White counterparts, and 35 points lower than their Asian American counterparts in 2015. In eighth grade, the gaps are even larger: Thirty-two and 47 points, respectively. Similarly, fourth grade Latino students scored 21 points lower than their White peers in fourth grade mathematics and 26 points lower in $8^{\text {th }}$ grade mathematics (NCES, 2015). Moreover, the likelihood of persistence in a STEM major is strikingly lower for UR students when compared to their White and Asian counterparts (Arcidiacono, Aucejo, \& Spenner, 2012).

When the data are disaggregated further by sex, we see that underrepresented (UR) males, and African American males in particular, face unique obstacles that have contributed to low achievement in STEM subjects. For example, NAEP data (2000-2013) indicate that African American boys underperform African American girls on the fourth grade mathematics assessment. This, in turn, has led to their underrepresentation in STEM degrees (Palmer, Davis, Moore, \& Hilton, 2010) and careers. Moreover, those UR males who do graduate from high school have completed fewer math, science, computer science, and technology courses compared to their White and Asian peers, and are less likely to take 'gatekeeper' courses such as PreCalculus and Calculus (NCES, 2016).

\section{Purpose Statement}

Although, only in the preliminary stages of data collection, the primary goal of this work is to address the challenge of broadening participation in STEM, particularly among UR boys by building on a pilot afterschool STEM program for UR boys. Specifically, this project proposes the STEM Engagement through Mentoring (SEM) model as a way to address the following questions:

1) In what ways do fathers/mentors motivate students to become aware of, interested in, and prepared for STEM careers?

2) To what extent does involvement in SEM shape the students' STEM identity?

3) What impact does working with the SEM program have on the self-efficacy of pre-service teachers with regards to teaching engineering education? 
The project team hypothesizes that our program model will provide a coherent set of experiences that will support students' preparedness and persistence in STEM subjects and motivation to pursue STEM careers, ultimately broadening participation of UR males in STEM education and careers.

\section{Program Background}

\section{St. Elmo Brady Academy (SEBA)}

Created in 2013 at the University of Illinois, the program on which the STEM Engagement through Mentoring (SEM) model is based, SEBA, is a STEM enrichment program that combines partnerships between STEM and education faculty at the University of Houston, with mentorship from the participants' fathers/caregivers and engineering undergraduates to provide hands-on STEM experiences to fourth and fifth grade underrepresented (UR) boys. Using this model, this program systematically exposes students to STEM disciplines, STEM professionals, and STEM graduate and undergraduate students with a strong emphasis on engineering and science competency. The program goals are to:

- Increase student awareness of STEM-related disciplines through hands-on experiences and engagement with STEM professionals;

- Motivate students to pursue education pathways for STEM-related careers;

- Provide students with engaging experiences that develop disciplinary-based knowledge and practices (e.g. writing in their scientific journal, practicing oral communication, and using common laboratory equipment).

The program meets three times per week (twice after school and once on Saturdays) for eight weeks each semester, for a total of 16 weeks during the school year. Eight weeks was selected to provide frequent interaction with students each semester, as literature suggests that early and often exposure to hands-on STEM experiences is crucial to the development of students' STEM interest and identity (Johnson, Peters-Burton, \& Moore, 2015). Each week, participants engage in hands-on, inquiry-based activities that follow the 5E model. The 5E Instructional Model includes 5 stages: engage, explore, explain, elaborate, and evaluate (Bybee et al., 2006) which help students explore topics each week. This instructional model is foundational to the program's inquiry-based philosophy.

During sessions, participants also learn about STEM pioneers, with a particular emphasis on professionals who also are from underrepresented groups. The program culminates with a community STEM fair, during which students demonstrate their knowledge to their teachers, mentors, and families. This STEM fair is also a mechanism for recruiting more student participants and school partners. This program was piloted at two elementary schools in Champaign, Illinois in 2014, and one elementary school in Houston, TX in the spring of 2017. 
Significance of Study

Male Mentors and STEM Identity

A key component of SEM is the participation of male mentors, including fathers, male relatives, and undergraduate students. Researchers have shown that parental support is linked to the development of young people's attitudes towards STEM, their willingness to participate in STEM education, and their persistence in STEM training (Adamuti-Trache \& Andres, 2008; Carrington, Tymms, \& Merrell, 2008; Hazari, Sonnert, Sadler, \& Shanahan, 2010). For example, a study by Sjaastad (2012) revealed that when parents engage in STEM, they become role models who help students "define" themselves as STEM learners. More importantly, Sjaastad found that parents can be role models without necessarily having a career within STEM.

Similarly, researchers and practitioners point to the importance of male mentors in the educational progress and career choices of male students (Davis, Grant, Bowles, \& Jeffries, 2015). As with parental involvement, mentoring can contribute to the creation of a community and environment that value and promote STEM education (Mondisa \& McComb, 2015). For example, Gordon and colleagues (2009) found that middle school African American male students paired with an African American male mentor had significantly greater academic success than their peers without a role model. Similarly, an evaluation of a STEM mentoring program found that the students formed a bond with their mentors, improved their understanding of the scientific method, and also increased their awareness of the science content covered in the program (Monk et al., 2014).

At the same time, less is known about how the mentoring process and the relationships that develop affect the mentors themselves. Instead, research on mentors often focuses on either the qualities of a good mentor (Hernandez, Estrada, Woodcock, \& Schultz, 2017) or the dispositions that make a person more likely to become a volunteer (Lee \& Won, 2011). College student mentors may also benefit from these opportunities. For example, the Monk et al. (2014) study found that mentoring improved the college students' science communication skills and led them to take more pride in their work. Similarly, Chen (2013) argued that while increasing minority recruitment efforts in STEM fields is important, attention must also be focused on retention of minority students who are currently in those fields. Mentoring others may offer minority students a way to feel more connected to their university and to their field. SEM proposes to build on this research base through the inclusion of male mentors and by studying the ways in which those mentors help shape students' STEM identities, and the ways in which the mentor experience shapes the mentors themselves.

\section{Engaging Pre-service Teachers in Engineering}

Mentoring on its own is not sufficient to help UR students learn challenging science and engineering concepts and practices. Students also need high quality materials and teachers; however, most science teachers are not prepared to teach engineering (Bybee, 2014; Hynes, 2012; Kaya, Newley, Deniz, \& Yesilyurt, 2017). According to research, K-12 teachers continue to feel ill-prepared when teaching engineering related concepts and this limitation is in part caused by the lack of pre-service teacher trainings on engineering education (Katechi, Pearson, 
\& Fader, 2009). Therefore, the SEM team proposes to investigate the extent to and ways in which participating in SEM affects the pre-service teachers' self-efficacy in teaching engineering. Currently, the members of the grant team, consisting of a faculty member from the teacher preparation program, are working towards formalizing a partnership. This endeavor will not only allow for the program to support expansion in additional elementary schools but will also help inform the program's practices with regards to incorporation of engineering design in science and mathematics teacher preparation. Moreover, the teacher preparation program is one of 45 additional STEM teacher preparation sites located in research universities around the U.S. As such, this research will also provide insights for teacher preparation nationwide.

Consequently, with the support of an ITEST grant from the NSF, the project team proposes to:

1) Formalize a partnerships with STEM teacher preparation program and create a structure for training and interaction between the pre-service teachers and the SEM mentors;

2) Work with fourth and fifth grade teachers at partner schools and the STEM teacher

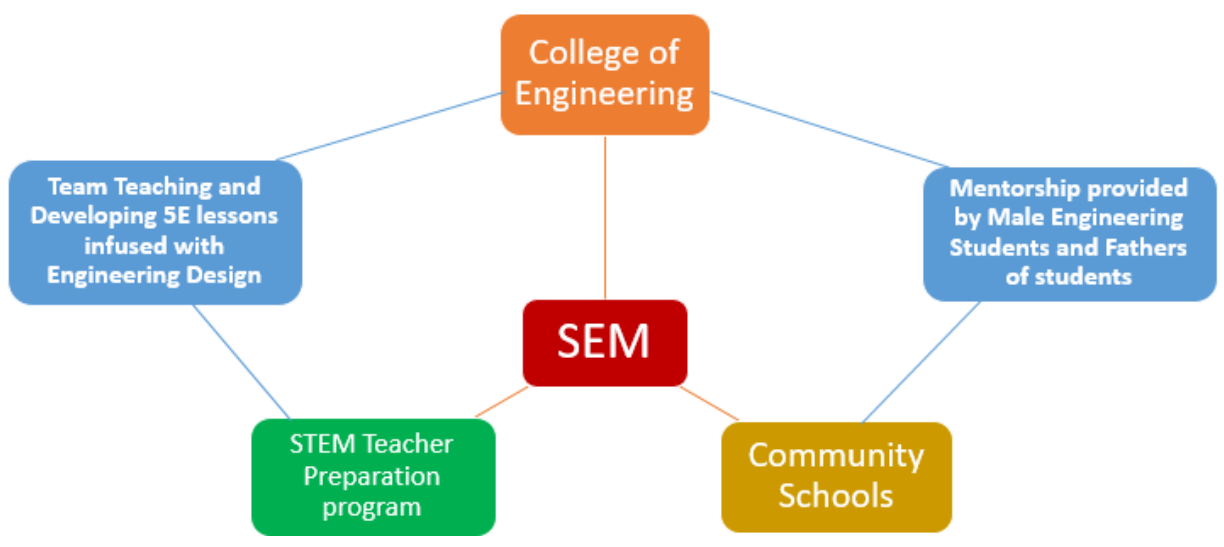

Figure 1. Program Partnership Overview preparation faculty and pre-service teachers to create a set of inquiry-driven modules that are aligned to the Texas mathematics and science standards as well as to the Next Generation Science Standards (NGSS) (see Figure 1).

\section{Program Pilots}

The Champaign, Illinois pilot was led by the program director (and program founder, Mr. Greer) and the program co-founder (Dr. Henderson) who developed lesson plans, led hands-on activities, and trained program staff (undergraduate and graduate engineering students). Lessons emphasized the engineering design process (Haik, Sivaloganathan, \& Shahin, 2015). Students were given open-ended scenarios and were tasked to identify and research problems, develop possible solutions, and then plan, test and improve their designed solutions.

The Houston pilot, initiated in the spring of 2017, combined the best practices learned from the earlier pilot and added a partnership with the University of Houston's secondary STEM teacher preparation program (i.e., teachHOUSTON). The teacher preparation program is a collaboration between the College of Natural Science and Mathematics and the College of Education. It is committed to combatting the shortage of qualified secondary math and science teachers through field-based teaching experiences. Furthermore, this program is one of 45 replication sites located throughout the U.S. of a nationally acclaimed teacher preparation model. As such, this partnership has potential to extend the impact of SEM on a national scale. Furthermore, the 
purpose of the nascent partnership was to ensure that lesson plans were aligned to follow the $5 \mathrm{E}$ Model which is foundational to the program's inquiry-based philosophy, and to provide the mathematics and science pre-service teachers with exposure to engineering design. The undergraduate mathematics and science majors who took part in the spring 2017 pilot were enrolled in a university course, Step 1: Inquiry Approaches to Teaching, which is an introductory course to teaching math and science through a hands-on approach. The Step 1 course provides students with opportunities to create lesson plans, teach, and engage with other field-based experiences, such as conducting classroom observations and receiving feedback on their own teaching.

\section{Preliminary findings}

Preliminary data from these pilots suggest that, after one year of program participation, $96 \%$ of the students who participated in SEBA in Champaign, IL were more interested in science, $92 \%$ were more confident in their science and mathematics classes, and $88 \%$ participated more in their science and mathematics classes (Greer, Henderson, Summers, \& Morphew, 2017).

Students in the Houston pilot reported in focus group interviews that they enjoyed the hands-on activities and were more interested in engineering as a result of their participation. Moreover, their interest and awareness of STEM careers (e.g., physics, mathematics, medicine, computer science, and engineering, among others) increased during the course of the four-month pilot. These preliminary findings are quite promising and speak to the potential impact of the proposed work.

Exit interviews with program mentors and the pre-service teachers, however, pointed to areas for improvement, including: 1) A more clear definition of the mentors' and fathers' roles, 2) More coordination between the mentors and pre-service teachers, 3) Lessons that are more hands-on and expose the students to more types of engineering, and 4) Additional opportunities to learn about STEM-related careers.

\section{Current Project Results}

Through NSF funding provided under the ITEST grant, the SEM project has begun work on extending the pilot and implementing it across inner city elementary surrounding the University of Houston area. Through lessons learned and implications from the preliminary findings, SEM has four essential program components that this project proposes to build on: 1) Hands-on lessons in science and engineering, 2) connections to UR male scientists and engineers, 3) an end of year community STEM fair, and the component that most distinguishes SEM from other STEM programs, 4) participation from father, adult male relatives, and/or male mentors.

1) Working with STEM faculty the program's creators are continuing to develop hands-on, engaging lessons that address vital STEM content topics. During the spring 2017 pilot, the SEM team worked with teachers at the pilot school to ensure the activities and sequence were aligned with the school's scope and sequence as well as with the Texas standards for fourth and fifth grade science (the Texas Essential Knowledge and Skills, TEKS). The lessons also were mapped onto a modified 5E model (Bybee et al., 2006) so that each day students were taught a different $5 \mathrm{E}$ lesson that was part of a weekly module. For example, during the 
conservation of energy unit, pre-service teachers taught a 5E lesson on Mechanical Energy on Tuesday, followed by a 5E lesson on Energy transformations on Thursday, and finally on roller coaster energy on Saturday. The Tuesday and Thursday lessons were each roughly 45 minutes and were taught by two different pairs of pre-service teachers. The Saturday lesson was either split into two 50 minute 5E lessons, or one 110 minute 5E lesson and was also divided between two pairs of pre-service teachers. Each lesson was aligned to the national Next Generation Science Standards (NGSS) and National Science Teachers Association (NSTA) standards for Engineering Design. Currently the project team is working on expanding the collection of lessons that integrate engineering design with crucial mathematics and science topics.

2) Once each week, prior to the 5-E module, students learn about different UR STEM professionals. Some of the professionals that students have learned about include: St. Elmo Brady, Lewis Howard Latimer, José Hernández-Rebollar, Neil deGrasse Tyson, and Luis Leloir. Students learned about their research, careers, and their personal and professional pathways, including where they went to school and what challenges they faced. The students took notes and participated in a discussion about what they learned. Students consistently demonstrated that they identified with the STEM professionals that they learned about by referring to themselves or each other by the STEM professionals' names. Students are also able to recall key information about scientists when asked in focus groups or in informal settings by program staff.

3) At the end of the spring semester, students planned and executed their own community STEM fair. For the fair, students worked in teams of two or three to select their favorite activity, created a poster and a presentation that includes a hands-on component, and presented that work to teachers, family, friends, mentors, and other community members. Additionally, pre-service teachers also volunteered to hold a science and engineering day that allowed all students enrolled to partake in various building activities. This helped elicit interest in the after school program and will, therefore, continue to be a part of the team's efforts.

4) Finally, the hallmark of the program, and what most distinguishes it from other afterschool STEM programs, is the participation of fathers, adult male relatives, and/or male mentors (i.e. fathers/caregivers). Fathers or male relatives of the boys are encouraged to attend Saturday sessions to conduct experiments alongside participants. Their participation is voluntary, but strongly encouraged. During the course of the program we discovered that it is challenging for fathers or male relatives to participate regularly. We are looking for ways to more strongly recruit fathers and caregivers, but in the meantime, our program staff has served as mentors. Program mentors included five UR male undergraduates majoring in engineering who attended each week's sessions and work with the boys. Mentors were recruited through partnerships with student STEM organizations such as the National Society of Black Engineers and Society of Hispanic Professional Engineers.

Preliminary data has revealed that the elementary students recognized and appreciated how the fathers served as role models in the SEM program. Over $90 \%$ of participants reported that they enjoyed and learned from having fathers involved with the program. In addition, the 
boys developed relationships with the mentors and saw, in their own words, "larger versions of themselves" who are successful college students studying engineering.

\section{Future expected results}

This is a work in progress, and thus, much of the data to answer the research questions 1) In what ways do fathers/mentors motivate students to become aware of, interested in, and prepared for STEM careers? 2) To what extent does involvement in SEM shape the students' STEM identity? 3) To what extent does involvement in SEM shape the mentors' STEM identity? 4)What impact does working with the SEM program have on the self-efficacy of pre-service teachers with regards to teaching engineering education? is currently being collected.

Research question 1 will be answered using semi-structured interviews with both the students and the adults as well as observations of sessions. Collecting multiple forms of data will allow the team to triangulate findings, in this way enhancing the richness as well as the validity and reliability (or trustworthiness) of the findings (Morse, Barrett, Mayan, Olson, \& Spiers, 2002). Interviews with adults will be one-on-one, and interviews with students will be small focus groups of two to three at time. Interviews will be guided by a semi-structured protocol focused on understanding participants' experiences in the program, and the ways in which those experiences affect (or do not affect) their perceptions of STEM and STEM careers. Interviews will be conducted at the end of the fall and spring semesters of each year of the grant. This semester our interviews will be conducted in May. The purpose of the observations is to witness the interactions among the students, mentors/fathers, and teachers. Researchers will take extensive field notes on the context, setting, and the participants' physical interactions and conversations. At least four sessions will be observed during each semester: two during the week after school, and two during the Saturday sessions. Additional observations will be added as needed to ensure that fathers or caregivers are observed.

To answer research question 2 the Student Attitudes toward STEM survey (Faber et al., 2013), which has a version designed for fourth and fifth grade students. The survey measures students' STEM identity as well as their interest in STEM education and careers.

Finally, in order to answer research question 3, which asks about the effect of working with SEM on the pre-service teachers' sense of self-efficacy, data will be collected in two ways: Interviews and surveys. Pre-service teachers will be interviewed individually at the end of each semester during their participation using a semi-structured interview protocol. The protocol will focus on understanding what program components were most important for enhancing (or not) their selfefficacy as STEM teachers. Data also will be collected using the Ohio State Teacher Efficacy Scale (OSTES; Tschannen-Moran \& Hoy, 2001); pre-service teachers will take the survey at the beginning and end of year during which they participate in the program during the grant period.

We expect to observe an increase in fourth and fifth grade UR male interest and awareness with regards to STEM related careers. Upon collaboration between engineering mentors and preservice teachers, we hypothesize that pre-service teachers will leave the program with a heightened efficacy in teaching mathematics and science topics through engineering design. 


\section{References}

Adamuti-Trache, M., \& Andres, L. (2008). Embarking on and persisting in scientific fields of study: Cultural capital, gender, and curriculum along the science pipeline. International Journal of Science Education, 30(12), 1557-1584. https://doi.org/10.1080/09500690701324208

Arcidiacono, P., Aucejo, E. M., \& Spenner, K. (2012). What happens after enrollment? An analysis of the time path of racial differences in GPA and major choice. IZA Journal of Labor Economics, 1(1), 5. https://doi.org/10.1186/2193-8997-1-5

Bybee, R. W., Taylor, J. A., Gardner, A., Van Scotter, P., Powell, J. C., Westbrook, A., \& Landes, N. (2006). The BSCS 5E instructional model: Origins and effectiveness. Colorado Springs, Co: BSCS, 5, 88-98.

Bybee, R. W. (2014). NGSS and the next generation of science teachers. Journal of science teacher education, 25(2), 211-221. https://doi.org/10.1007/s10972-014-9381-4

Carrington, B., Tymms, P., \& Merrell, C. (2008). Role models, school improvement and the 'gender gap'- do men bring out the best in boys and women the best in girls? British Educational Research Journal, 34(3), 315-327. https://doi.org/10.1080/01411920701532202

Chen, X. (2013). STEM Attrition: College Students' Paths into and out of STEM Fields. Statistical Analysis Report. NCES 2014-001. National Center for Education Statistics.

Davis O., Grant C., Bowles T., Jeffries R. (2015). Successfully mentoring diverse male students in Engineering at North Carolina State University: An engaged approach. QScience Proceedings, 12. https://doi.org/10.5339/qproc.2015.elc2014.12

Faber, M., Unfried, A., Wiebe, E. N., Corn, J., Townsend, L. W., \& Collins, T. L. (2013). Student attitudes toward STEM: The development of upper elementary school and middle/high school student surveys. In the Proceedings of the 120th American Society of Engineering Education Conference.

Gordon, D. M., Iwamoto, D., Ward, N., Potts, R., \& Boyd, E. (2009). Mentoring urban Black middle-school male students: Implications for academic achievement. The Journal of Negro Education, 78(3), 277.

Greer, R. P., Henderson, J. A., Summers, R. G., \& Morphew, J. W. (2017, June). Engagement in Practice: Success Gleaned from the St. Elmo Brady STEM Academy. In 2017 ASEE Annual Conference \& Exposition. doi:105860/choice.41-1054

Haik, Y., Sivaloganathan, S., \& Shahin, T. M. (2015). Engineering design process. Nelson Education.

Hazari, Z., Sonnert, G. Sadler, P.M., \& Shanahan, M.-C. (2010). Connecting high school physics experiences, outcome expectations, physics identity, and physics career choice: A gender study. Journal of Research in Science Teaching, 47(8), 978-1003. https://doi.org/10.1002/tea.20363 
Hernandez, P. R., Estrada, M., Woodcock, A., \& Schultz, P. W. (2017). Protégé Perceptions of High Mentorship Quality Depend on Shared Values More Than on Demographic Match. The Journal of Experimental Education, 85(3), 450-468.

https://doi.org/10.1080/00220973.2016.1246405

Johnson, C. C., Peters-Burton, E. E., \& Moore, T. J. (Eds.). (2015). STEM road map: A framework for integrated STEM education. Routledge.

Katehi, L., Pearson, G., \& Feder, M. (2009). Engineering in K-12 education: Understanding the status and improving the prospects. Washington DC: National Academy Press.

Kaya, E., Newley, A. D., Deniz, H., \& Yesilyurt, E. (2017, June). Board \# 115 : EEGRC Poster: Improving Pre-service Elementary Teachers' Nature of Engineering Views with the Use of EV3 Robotics. In 2017 ASEE Annual Conference \& Exposition. Retrieved from https://peer.asee.org/27698

Lee, Y. J., \& Won, D. (2011). Attributes influencing college students' participation in volunteering: a conjoint analysis. International Review on Public and Nonprofit Marketing, 8(2), 149. https://doi.org/10.1007/s12208-011-0074-9

Mondisa, J. L., \& McComb, S. A. (2015). Social community: A mechanism to explain the success of STEM minority mentoring programs. Mentoring \& Tutoring: Partnership in Learning, 23(2), 149-163. https://doi.org/10.1080/13611267.2015.1049018

Monk, M. H., Baustian, M. M., Saari, C. R., Welsh, S., D’Elia, C. F., Powers, J. E., Gatson, S., Francis, P. (2014). EnvironMentors: Mentoring At-Risk High School Students through University Partnerships. International Journal of Environmental \& Science Education, 9(4), 385397.

Morse, J. M., Barrett, M., Mayan, M., Olson, K., \& Spiers, J. (2002). Verification strategies for establishing reliability and validity in qualitative research. International journal of qualitative methods, 1(2), 13-22. https://doi.org/10.1177/160940690200100202

National Center for Education Statistics. (2015). The nation's report card: 2015 mathematics \& reading assessments. Washington DC: U.S. Department of Education, Institute of Education Sciences. Retrieved from https://www.nationsreportcard.gov/

reading_math_2015/\#mathematics/groups?grade=4

Palmer, R. T., Davis, R. J., Moore III, J. L., \& Hilton, A. A. (2010). A Nation at Risk: Increasing College Participation and Persistence Among African American Males to Stimulate US Global Competitiveness. Journal of African American Males in Education, 1(2).

President's Council of Advisors on Science and Technology (PCAST). (2010). Prepare and inspire: K-12 education in science technology, engineering and math (STEM) for America's future. Washington, DC: Executive Office of the President. 
Sjaastad, J. (2012). Sources of Inspiration: The role of significant persons in young people's choice of science in higher education. International Journal of Science Education, 34(10), 16151636. doi:10.1080/09500693.2001.590543

Tschannen-Moran, M., \& Hoy, A. W. (2001). Teacher efficacy: Capturing an elusive construct. Teaching and teacher education, 17(7), 783-805. https://doi.org/10.1016/S0742-051X(01)000361 